\title{
Anomalous electric field changes and high flash rate beneath a thunderstorm in northeast India
}

\author{
S D Pawar, P Murugavel and V Gopalakrishnan \\ Indian Institute of Tropical Meteorology, Pune 411 008, India.
}

In spite of many experimental and theoretical studies the relationships between storm dynamics, severe weather, and lightning activity have been least understood. Measurements of electric field made under a severe thunderstorm at a northeastern Indian station, Guwahati, India are reported. Lightning flash rate increases drastically to about 84 flashes per minute (fpm) during the active stage which lasted for about 7 minutes, from about 15 flashes per minute during the initial phase of thunderstorm. Sudden increase in lightning flash rate ('lightning jump') of about $65 \mathrm{fpm} / \mathrm{min}$ is also observed in the beginning of the active stage. The dissipating stage is marked by slow and steady decrease in lightning frequency. Despite very high flash rate during the active stage, no severe weather conditions are observed at the ground. It is proposed that the short duration of the active stage might be the reason for the non-observance of severe weather conditions at the ground. Analysis of Skew-t graph at Guwahati suggests that vertical distribution of Convective Available Potential Energy (CAPE) also may play some role in non-occurrence of severe weather at ground in spite of large lightning flash rate and lightning jump observed in this thunderstorm. Further, all electric field changes after a lightning discharge indicates the presence of strong Lower Positive Charge Centers (LPCC) in the active and dissipation stages. This suggests that LPCC plays an important role in initiation of lightning discharges in these stages.

\section{Introduction}

Measurements of electric field or lightning-induced electric field-changes at ground surface have been used for a long time to infer the in-cloud charge distribution and the changes in the distribution caused by lightning discharges (Standler and Winn 1979; Brook et al 1982; Krehbiel et al 1983; Maier and Krider 1986; Jacobson and Krider 1976; Livingston and Krider 1978; Pawar and Karma 2004). Recovery curves of the surface electric field after lightning discharges have been used to study the electrification processes in thunderclouds (e.g., Wilson 1920; Wormell 1930; Deaver and Krider 1991). However, if the space charge produced due to coronae ions in the sub-cloud layer is large enough, the inferences drawn from such studies about cloud electrification will be erroneous as the field at the ground is the summation of fields due to charges in the thundercloud and the space charge in the sub-cloud layer (Standler and Winn 1979; Soula and Chauzy 1991; Pawar and Kamra 2002).

Many studies in the past have tried to show that lightning characteristics can be used to categorize the thunderstorms and predict the severity of thunderstorms, because severe weather is associated with unique lightning characteristics. For example, MacGorman et al (1989) found that cyclonic shear at $1.5 \mathrm{~km}$ is positively correlated with CG flash rate and negatively correlated with IC discharges. Williams et al (1999) have studied the behaviour of total lightning activity in severe Florida thunderstorms. They found that the most obvious and systematic characteristics of severe thunderstorm was the rapid increase in

Keywords. Electric field changes; thunderstorm in northeast India; recovery curves. 
total lightning flash rate, 1-15 minutes prior to severe weather manifestation such as high surface wind, hail and tornado at the ground. The increase in total lightning flash rate varies from about 20 to over $100 \mathrm{fpm} / \mathrm{min}$. It has been found that the total lightning flash rate exceeds $60 \mathrm{fpm}$ with some value reaching $500 \mathrm{fpm}$ in the severe thunderstorms. Recent studies by McCaul et al (2002) and Wiens et al (2005) also show that lightning jumps coincide with storm intensification prior to and during tornadogenesis. Steiger et al (2007) found that a total lightning hole was associated with an intense, non-tornadic supercell; whereas none of the supercells exhibited a lightning hole in their observations over Dallas-Fort Worth, Texas. Kaltenböck et al (2009) also have reported more CG lightning during days with severe weather, especially with hail, wind and precipitation events from organized and clustered thunderstorm systems.

The northeastern part of India is known to experience very severe thunderstorms during the pre-monsoon season, locally known as 'Nor'wester'. The dynamics and features of Nor'wester are described in detail by Koteshwaram and Srinivasan (1958) and Kanjulal et al (1989). The airflow over Gangetic Plains and the adjoining areas has a shallow layer of moist southerlies/southwesterlies from the Bay of Bengal near the ground and dry westerlies of continental origin above. The layer of transition between these two airstreams is stable in which moisture decreases very rapidly with height. Although the low-level inversion inhibits growth of convective clouds, its presence prevents the penetration of convection into the layers above. Thus, the moist layer increases in moisture and warmth thus increasing Convective Available Potential Energy (CAPE) enormously which is a favourable condition for a severe Nor'wester outbreak. Advection of warm air in the lower levels and cold air in the upper levels will increase the conditional instability in the atmosphere and favour outbreak of severe thunderstorms (Koteswaram and Srinivasan 1958; Raman and Raghavan 1961; Krishna Rao 1966).

Guha and De (2009) have studied the electrical characteristics of thunderstorms occurring in northwest region of India using sferics and they found some distinct peaks in the VLF range between 1.5 and $6 \mathrm{kHz}$. The electrical characteristics of such severe Nor'westers have been studied for the first time using surface measurements of electric field and here we report our observations of electric field changes and recovery curves of lightning discharges made below an isolated thunderstorm at Guwahati $\left(26.10^{\circ} \mathrm{N}, 91.58^{\circ} \mathrm{E}\right)$. The evolution of lightning during different stages of the thunderstorm is also discussed.

\section{Instrumentation}

Atmospheric electric field $(E)$ is measured by a vertical field mill as described by Kamra and Pawar (2007). It consists of one stator and a rotor plate of symmetric shape and size. The field mill is kept in a 30-cm deep pit with sensor plates flush to ground surface. The time constant of the field mill is adjusted to $0.1 \mathrm{~s}$. The field mill can measure the electric field in the range of $\pm 12 \mathrm{kV} / \mathrm{m}$ and the response of the field mill in this range is found to be linear during the calibration. The sensitivity of the field mill is $\pm 10 \mathrm{~V} / \mathrm{m}$ and noise level is well below $\pm 10 \mathrm{~V} / \mathrm{m}$. The electrical zero of field mill is checked periodically by applying ground potential to a plate placed $10 \mathrm{~cm}$ above the sensors and is found to be remaining constant during the observational period. The data has been sampled at the rate of 10 samples/s. We have followed the convention that the fair-weather electric field is of negative polarity. A field change of minimum $\pm 600 \mathrm{~V} / \mathrm{m}$ occurring in a period of $<1 \mathrm{~s}$ is taken as a lightning-induced change. One polarity electric field immediately followed by another polarity electric field change has been taken as one lightning discharge. Further, a positive (negative) fieldchange means removal of positive (negative) charge from overhead.

\section{Observations}

\subsection{Meteorological observation}

The vertical profiles of air temperature and dew point temperature are obtained from upper air radiosonde observations made at 1730 IST (Indian Standard Time corresponding to $82.5^{\circ} \mathrm{E}$ longitude) on April 20, 2007 about $30 \mathrm{~km}$ from the observational site. As seen from figure 1, temperature profile shows that there is a considerable buildup of Convective Available Potential Energy (CAPE) of about $2200 \mathrm{~J} \mathrm{~kg}^{-1}$ and the Level of Free Convection (LFC) is at $841 \mathrm{mb}$, which are conducive for convection and development of thunderstorm. The thunderstorm developed $2-3 \mathrm{~km}$ north of the observatory at about 2347 IST. Within a few minutes, it moved over the observatory. This thunderstorm lasted about one hour and gave moderate rainfall about $5 \mathrm{~mm}$. Winds at surface remained calm or low during whole thunderstorm period. The visual observations and the pattern of electric field changes induced by lightning, which remained similar until the last lightning flash, suggested that thunderstorm was stationary over the observational site during its lifetime. The sky cleared up completely after the rain. 


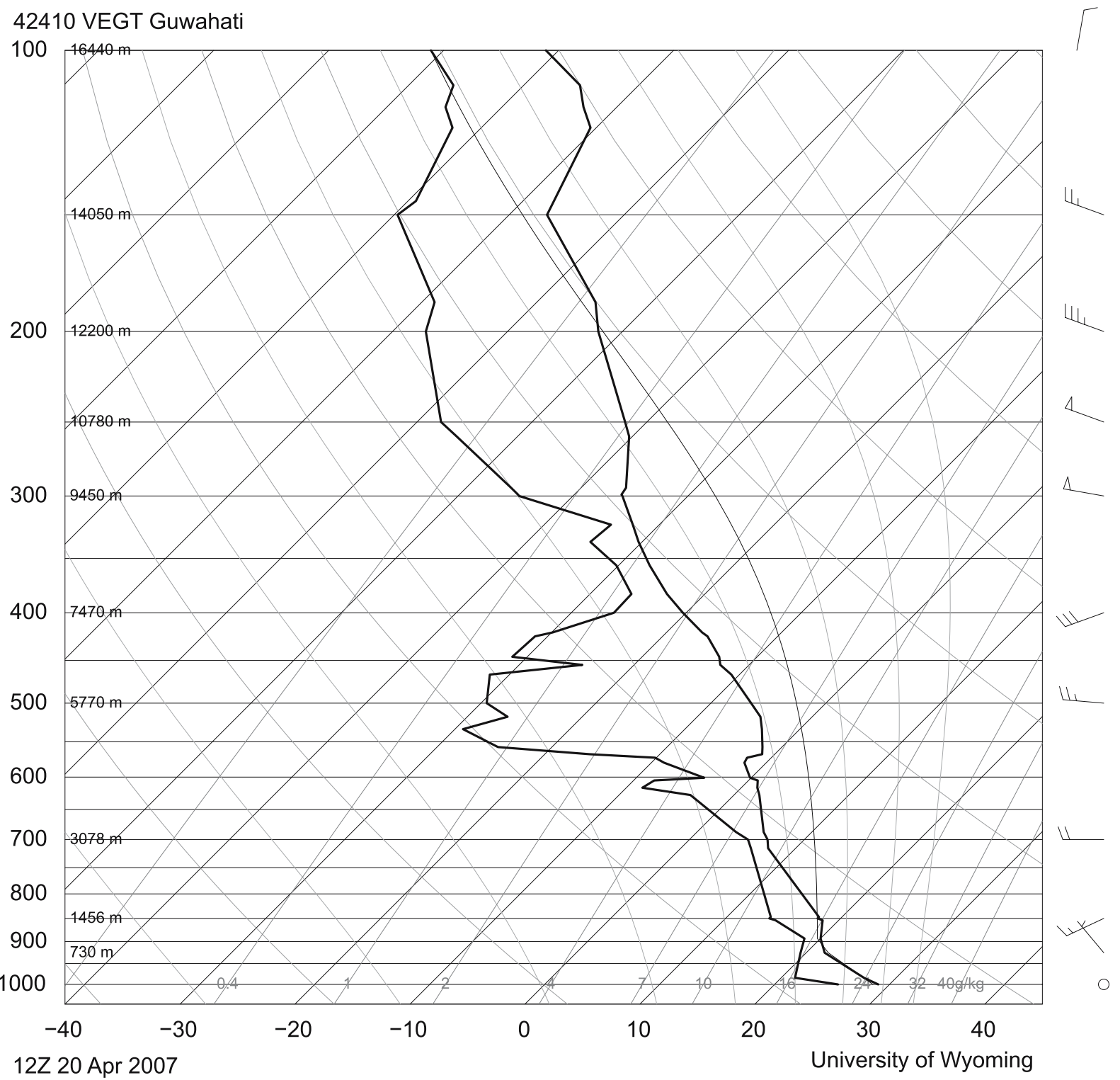

SLAT26.10 SLON91.58 SELV54.00 SHOW0.18 LIFT-3.97 LFTV-4.91 SWET309.1 KINX36.60 (1) CTOT20.30 VTOT24.50 TOTL44.80 CAPE2014. CAPV2214. CINS-6.82 CINV-0.84 (1) ELV196.3 EQTV196.2 LFCT841.8 LFCV877.4 BRCH63.63 BRCV69.95 (1) (1) MLTH301.7 MLMR16.89 THCK5716. PWAT48.19

Figure 1. Skew-t graph of radiosonde observations made at 1730 IST on April 20, 2007 at Guwahati.

\subsection{Lightning flash rate}

Figure 2 shows the electric field measured at ground during the thunderstorm. First lightning discharge is recorded by field mill at about 2352 IST. As shown in figure 3 , we have divided this thunderstorm into three stages - initial, active and dissipating stages based on lightning flash rate. The initial stage lasted for about 20 minutes and lightning flash rate remained between 10 and $20 \mathrm{fpm}$. The active stage started at about 0012 IST and lasted only for 7 minutes up to 0019 IST. The lightning flash rate increases sharply to about $84 \mathrm{fpm}$ within 1 to 2 minutes and remains between 75 and $85 \mathrm{fpm}$ during active stage. In the active stage, flash rate increases at a rate of about $65 \mathrm{fpm} / \mathrm{min}$. As described by Williams et al (1999) such a sudden jump in lightning flash rate is sometimes associated with the increase in updraft and severe weather at the ground. In the dissipation stage, the flash rate decreased rather slowly and reached near to zero at about 0043 IST.

\subsection{Electric field changes and recovery curves}

Figure 4 shows the electric field changes and recovery curves after the lightning discharges in the initial stage. In this stage, electric field changes induced by lightning are negative indicating removal of net negative charge overhead. The recovery curves of electric field after lightning discharges are linear indicating building up of negative charge. Figure 5(a and b) shows electric field record for $12 \mathrm{~s}$ at the start and end of active stage respectively. In this stage, when lightning flash rate is very high, the electric field changes caused by 


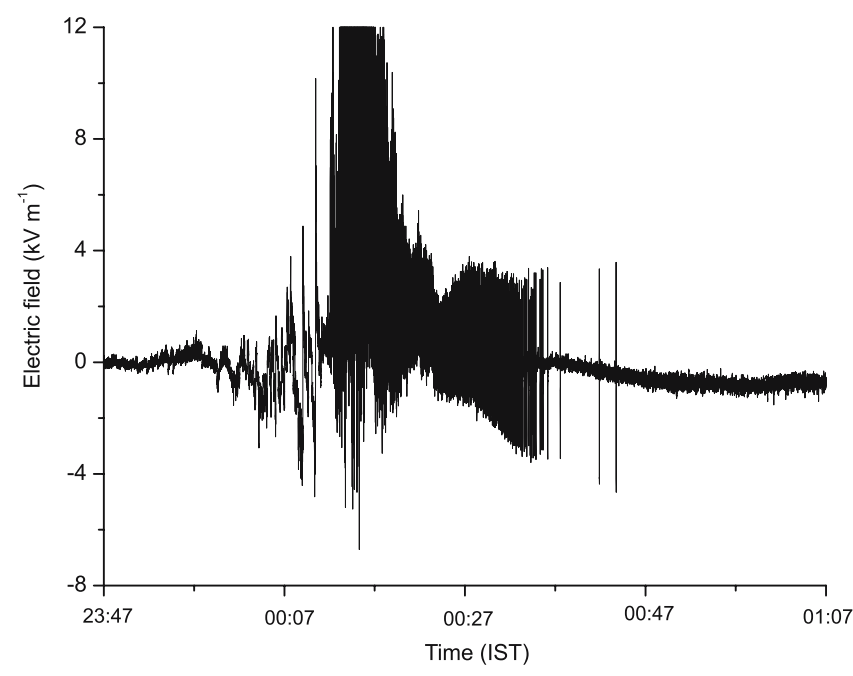

Figure 2. Electric field observed at the surface during the thunderstorm.

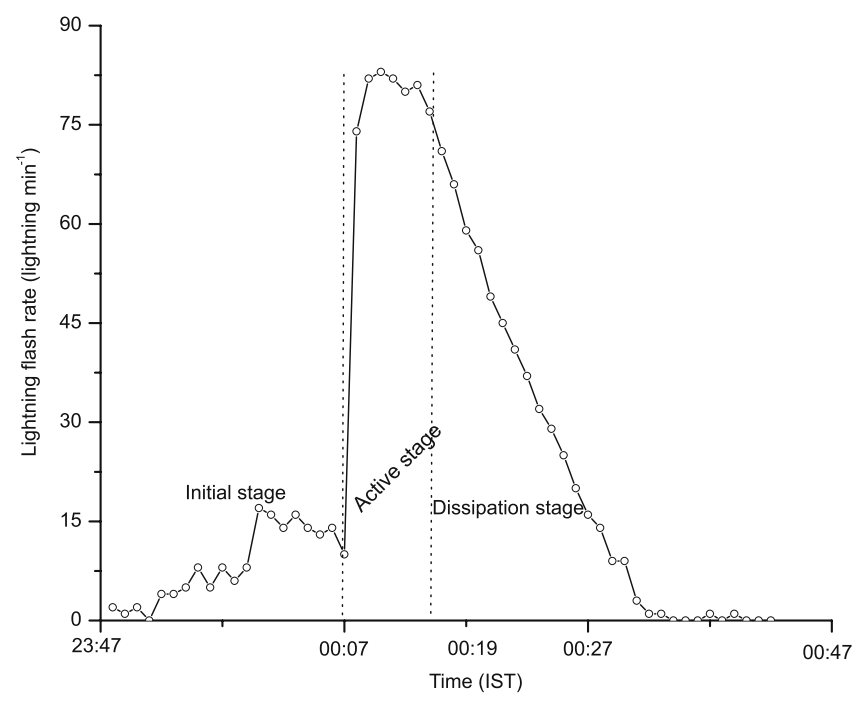

Figure 3. Variation of lightning flash rate during different stages of the storm.

lightning are different from those reported earlier by Livingston and Krider (1978). It is seen from figure 5(a and $\mathrm{b})$ that all the electric field changes induced by lightning in this stage are similar. Each discharge has two field changes; negative one immediately follows the first one, which is always positive. It is worthy to note that both these electric field changes are of equal magnitude. Pawar and Kamra (2004) have already reported such two-polarity electric field changes, one followed immediately by another. They have attributed this to two different lightning discharges of opposite polarity. It is most likely that these two electric field changes are associated with two lightning discharges, one triggered by another. However, it is also possible that these positive and negative field changes are associated with a stroke or

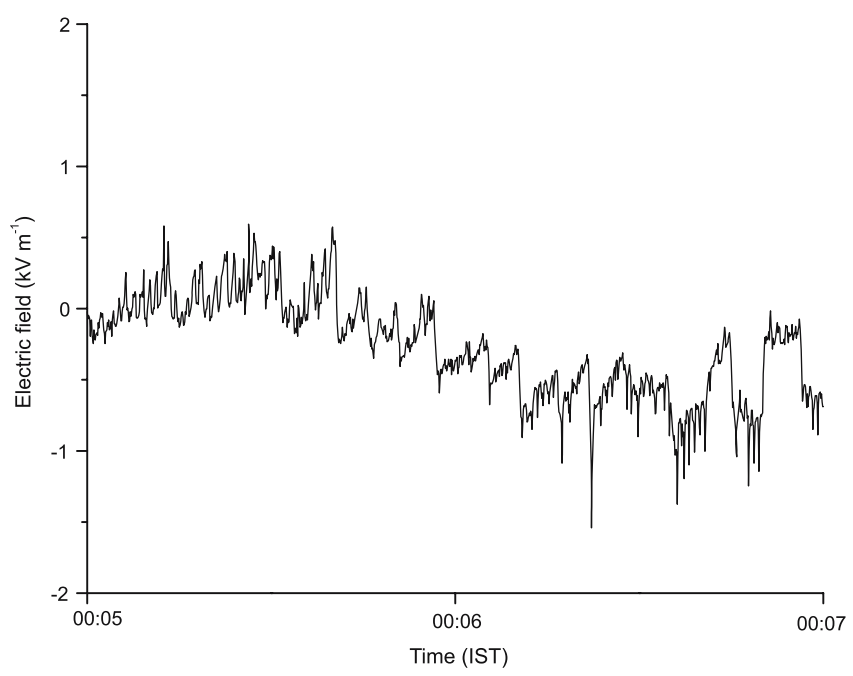

Figure 4. Surface electric field records on an expanded time scale obtained during the initial stage of the thunderstorm.

inter-stroke processes of single lightning discharge and hence, we have counted this as one lightning discharge (for example in figure $5 \mathrm{a}$, we have counted 16 flashes). As shown in figure 5 (a and b), the pre-discharge value of electric field was about $1-2 \mathrm{kV} / \mathrm{m}$ and recovery curves are rarely observed between two lightning discharges due to high flash rate. These recovery curves indicate building up of negative charge overhead. Even though we do not have any information about the nature of discharges (Cloud-to-Ground (CG) or Intra-Cloud (IC)), as the thunderstorm is overhead (no question of reversal distance), the electric field changes clearly suggest that first discharge is removing net positive and second discharge is removing net negative charge from overhead. Dissipation stage started at about 0019 IST is marked by slow and steady decrease in lightning flash rate at the rate of 4-7 fpm $/ \mathrm{min}$. Figure 6 (a and b) shows the electric field record on extended time scale in this stage. The electric field changes induced by lightning are similar to that in active stage, with the only difference being the initial positive electric field change is less compared to negative field change immediately followed by it. Since the pre-discharge electric field value is close to zero or little positive and the time gap between two lightning discharges is more compared to active stage, the recovery curves are clearly seen here. The recovery curves in this stage also indicate the building up of negative charge overhead.

\subsection{End-Of-Storm-Oscillation (EOSO)}

Electric field record (figure 1) does not show strong signature of EOSO. The electric field have reversed its sign during dissipation stage of thunderstorm, however the magnitude of the negative electric field 


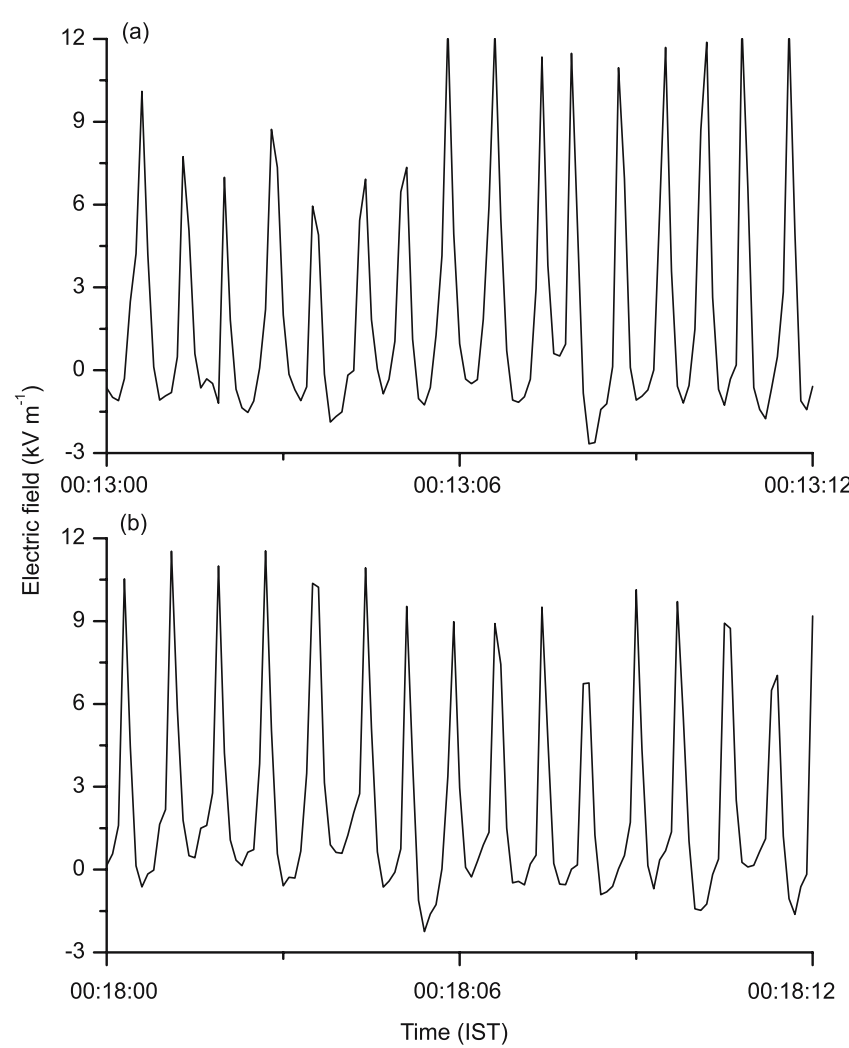

Figure 5. Surface electric field plotted on an expanded time scale during start of active stage (a), and end of active stage (b) of the thunderstorm.

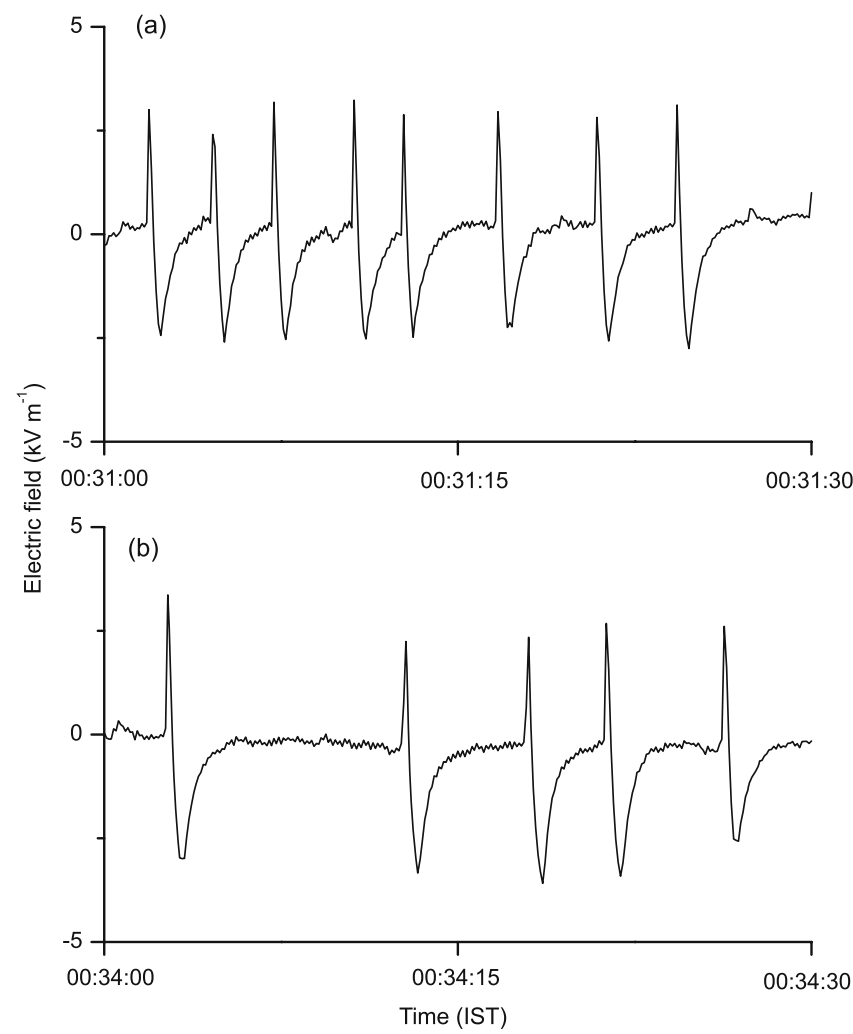

Figure 6. Surface electric field plotted on an expanded time scale during start of dissipation stage (a) and end of dissipation stage (b) of the thunderstorm. is very small (less than $-1 \mathrm{kV} / \mathrm{m}$ ). It is possible that the thundercloud might have moved away from observational sight. As shown by MacGorman and Rust (1998) the magnitude of the electric field is very sensitive to the distance of thundercloud from observational sight and therefore signature of EOSO is weak. However, the visual observations as well as the pattern and magnitude of electric field changes induced by lightning have remained similar until the last lightning flash. This suggests that the thunderstorm might have not moved away from the observatory during its lifetime. Moore and Vonnegut (1977) have suggested that primary swing to negative surface electric field values during EOSO are due to expose of the upper positive charge of the clouds by the downdrafts occurring in dissipating stage of thunderstorms. In our observations, pre-discharge value of electric field has increased up to 3 to $4 \mathrm{kV} / \mathrm{m}$ during active stage. However, during the dissipation stage, pre-discharge values of electric field does not show swing to negative value, however its magnitudes remain small. This may be due to the absence of well-developed upper positive charge region or strong downdraft during dissipation stage. The nature of electric field changes induced by lightning are similar in both active and dissipation stages and the only difference is in magnitude (figures 5 and 6), which indicates that the electrical structure of cloud has remained same during these stages. Therefore, the absence of sufficiently strong downdraft to remove or push aside lower charges and expose upper positive charge region to ground may be the main cause for observing weak EOSO in this storm.

\section{Discussion}

\subsection{Lightning flash rate}

Williams et al (1999) have shown that the total flash rate for severe thunderstorms generally exceeds $60 \mathrm{fpm}$ with few extreme values reaching $500 \mathrm{fpm}$. They have also reported that the most obvious and systematic characteristics of severe thunderstorms is the rapid increase in intra-cloud flash rate $1-15 \mathrm{~min}$ prior to severe weather manifestation at the ground. Such a sudden increase termed as 'lightning jumps' (Williams et al 1999), are found to vary in magnitude from about 20 to over $100 \mathrm{fpm} / \mathrm{min}$. Recently Schultz et al (2009) have studied the positive correlation between lightning jumps and the manifestation of severe weather in thunderstorms occurring across the Tennessee Valley and Washington D.C. To predict the severity of thunderstorms they developed lightning jump algorithms using the data obtained from 
85 thunderstorms and from their study it is concluded that the lightning jump algorithms have the potential to indicate storm severity regardless of environment. Both the high flash rate and lightning jump, generally associated with thunderstorms of those producing severe weather at ground, are noted in our observations also. The peak value of total flash rate has reached up to $84 \mathrm{fpm}$ and the magnitude of lightning jump is about $65 \mathrm{fpm} / \mathrm{min}$. It should be noted that, if we count positive and negative electric field changes immediately followed by one another as two lightning discharges (which is most likely), then the peak lightning rate and lightning jump would have been double of what we have reported in figure 3. It is also to be noted here that we have observed such high lightning rate for only about 7 minutes whereas Williams et al (1999) have observed the phenomenon for a longer duration. Severe weather, such as damaging wind, hail, etc., is observed at ground 2-20 min after the lightning jump in their observations. However, in spite of such a high total flash rate and high value of lightning jump, we have not observed any severe weather at ground. This suggests that the intense updraft was too short-lived to permit severe weather at ground. Without radar or any other meteorological observations it is very difficult to find the cause of sudden increase of total flash rate (or updraft) and sustaining of it only for short time. However, our observations clearly demonstrate that in addition to high flash rate and lightning jump, duration of such high flash rate is also an important factor for the manifestation of severe weather at ground. Schultz et al (2009) have also reported in their study that in spite of a surge in total lightning no severe weather was reported. They attributed this in part to lack of observations (i.e., the thunderstorm occurs in a remote part of the region) or the inexact nature of thunderstorms (i.e., one thing does not always lead to the observance of another). In our observations, lack of observations may not be the reason because this thunderstorm was overhead of observatory and no severe weather was observed during thunderstorm period. Moreover, there was no report of damage in local news papers.

Many observational studies have shown that updraft velocity and volume of updraft exceeding $10 \mathrm{~ms}^{-1}$ show good correlation with total lightning (Lang and Rutledge 2002; Wiens et al 2005). Deierling and Petersen (2008) have observed that the updraft volume above $-5^{\circ} \mathrm{C}$ level with vertical velocities greater than 5 and $10 \mathrm{~m} \mathrm{~s}^{-1}$ is well correlated to mean total lightning flash rate. However, they found no correlation of total lightning flash rate either with the maximum or with the mean updraft speeds in the charging zone. As shown in figure 1, the total CAPE is not very high $(2214 \mathrm{~J})$ on that day, however in the temperature region between $-10^{\circ} \mathrm{C}$ and $-25^{\circ} \mathrm{C}$ the CAPE shows higher values, which indicates that updraft velocity would be maximum in that region of thundercloud. As shown by Deierling and Petersen (2008), in our observations also the mean total lightning activity is well correlated with the updraft volume above the $-5^{\circ} \mathrm{C}$. However, the mean updraft speeds in the charging zone is not well correlated with total lightning flash rate. Therefore, the higher CAPE value in the region between $-10^{\circ}$ and $-25^{\circ} \mathrm{C}$ may be responsible for high lightning flash rate observed in this thunderstorm. The total CAPE which is not very high in this case may be the reason for nonoccurrence of severe weather at ground. We are aware that the environmental conditions might be slightly different at the time of development of this thunderstorm than those of the conditions shown in figure 1. More numerous observations supported by radar measurements are required to confirm the relationship between updraft volume and total lightning flash rate.

It has been recognized that local orography also plays an important role in producing the strong updrafts necessary for the deep convective events (Bourscheidt et al 2009; Goswami et al 2010). Bourscheidt et al (2009) in their study in south Brazil have shown that the terrain slope has more influence than altitude on the thunderstorm occurrence and lightning activity. Goswami et al (2010) have shown that the unique topographic features of the northeastern Indian region play an important role in occurrence of extreme rain events in that region. They have shown that the steep topographic gradient rather than altitude is responsible for producing deep convections. Their analysis suggests that the convective heating associated with the synoptic events interact with mountains to generate gravity waves and strong updrafts associated with the gravity wave with much smaller spatial scale may be responsible for generating very deep convection on a small scale leading to the extreme events. It is possible that in the thunderstorm presented here, the strong updraft may be associated with a gravity wave generated by local orography and that may be the reason for high lightning flash rate in spite of low CAPE value.

\subsection{Electric field changes and recovery curves}

Even though no severe weather is observed at ground during this thunderstorm, the high flash rate and lightning jump certainly suggest that this thunderstorm had vigorous updraft in mixed phase region and large vertical depth. In initial stage, electric field changes and recovery curves indicate that the normal positive dipole charge 
structure of cloud (figure 4). However, in the active stage the electric field changes and recovery curves indicate a complicated charge structure. The positive electric field changes produced by lightning in this stage are due to reduction of net positive charge from overhead. This suggests the presence of strong lower positive charge pockets (LPCC) in the cloud. It has been found that the LPCC plays an important role in initiating $\mathrm{CG}$ discharge from main negative charge region (e.g., Williams 1989; Williams 2001; Mansell et al 2002; Marshall and Stolzenburg 2002; Pawar and Kamra 2004). However, some observations suggest that strong and widespread LPCC can inhibit negative leaders from reaching ground (Qie et al 2005). Wiens et al (2005), during the Severe Thunderstorm Electrification and Precipitation Study (STEPS), have reported that in a tornadic supercell during the first hour of lightning activity, there are no CG flashes of either polarity even though the lightning mapping array data strongly suggests the presence of a lower positive charge region beneath a negative charge region. These observations also suggest that stronger LPCC than normal can inhibit CG discharges. In our observations, for about 35 minutes, i.e., from 0012 to 0047, every positive electric field change is immediately followed by negative electric field change. This systematic behaviour of electric field changes in active and dissipation stages clearly shows that in the active stage either all the lightning discharges are initiated from LPCC or removal of LPCC by a lightning discharge has triggered another discharge from main negative charge region. Removal of LPCC can initiate IC discharge between upper positive charge region and main negative charge region by increasing electric field between them, as explained by Pawar and Kamra (2004) or it can initiate CG discharge from midlevel negative charge region as observed by Qie et al (2005). We propose that our observations of initial positive electric field changes are due to IC discharge from LPCC and main negative charge region. The negative electric field change followed by it can be a CG discharge from main negative charge region or IC discharge between main negative and upper positive charge regions. Simultaneous measurements of electric field or electric field changes at multiple stations are required to locate the charge centers within the cloud (Krehbiel et al 1979). Alternative technique described by Ravichandran and Karma (2004) uses electric field vector measured by spherical field mill and acoustic signals to calculate the location and magnitude of the charge destroyed by lightning. Therefore, conclusions drawn by us about charge structure of this thundercloud are just a speculation and many other explanations can exist for these observations. However, based on our earlier observations and available literature, it is the most possible explanation for these observations.

Many studies have shown (Standler and Winn 1979; Soula and Chauzy 1991; Pawar and Kamra 2002) that the space charge produced by corona discharges can affect on surface measurement of electric filed and the inferences drawn from such measurements about cloud electrification can be erroneous as the field at the ground is the summation of fields due to charges in the thundercloud and the space charge in the sub-cloud layer. However, in this study as suggested by Krider and Musser (1982), there may not be much corona discharges and space charge in sub-cloud layer because of high frequency of lightning during the initial stage and active stage of thunderstorm. In the dissipation stage as shown in figure 6 , the magnitude of electric field between two discharges is very less; therefore, there is no possibility of corona discharges. Hence, our observations are not affected by the space charge produced by corona discharges. Moreover, major conclusions of this study is based on high lightning flash rate observed in an isolated thunderstorm and estimation of flash rate is not affected by space charges in the sub-cloud layer.

\section{Conclusions}

In spite of many experimental and theoretical studies the robust relationships between storm dynamics, severe weather, and lightning activity have not been found (Steiger et al 2007). We have reported a thunderstorm with peak total lightning flash rate of $84 \mathrm{fpm}$, and with sudden increase in flash rate (lightning jump) of about $65 \mathrm{fpm} / \mathrm{min}$. In spite of such a large lightning flash rate and lightning jump no severe weather is observed at ground. Winds are very low during whole thunderstorm period and only $5 \mathrm{~mm}$ rain is recorded during the thunderstorm. Therefore, our observations strongly suggest that high flash rate or lightning jump may not always be associated with severe weather at ground.

The electric field changes after lightning discharges during active and dissipation stages suggest that strong LPCC can shield the main negative charge region and inhibit negative CG discharge and lightning discharge from main negative charge region is possible only after removal of some charges from LPCC.

\section{Acknowledgements}

The authors are grateful to Dr A K Baruah and Dr R Barman, Assam Science and Technology Council (ASTEC), Guwahati and Dr Jeelani, 
Regional Science Centre, Khanapara for providing logistics during this experiment. They also acknowledge the Department of Science and Technology, Government of India, for funding this study under Severe Thunderstorm-Observation and Regional Modeling (STORM) program.

\section{References}

Brook M, Nakano M, Krehbiel P and Takeuti T 1982 The electrical structure of the Hokuriku winter thunderstorms; J. Geophys. Res. 87 1207-1215.

Bourscheidt V, Juniora $\mathrm{O} P$, Naccarato $\mathrm{K} \quad \mathrm{P}$ and Pintoa I R C A 2009 The influence of topography on the cloud-to-ground lightning density in South Brazil; Atmos. Res. 91 508-513.

Deaver L and Krider E 1991 Electric fields and current densities under small Florida thunderstorms; J. Geophys. Res. 96 D12, doi: 10.1029/91JD02264.

Deierling W and Petersen W A 2008 Total lightning activity as an indicator of updraft characteristics; J. Geophys. Res. 113 D16210, doi: 10.1029/2007JD009598.

Goswami B B, Mukhopadhyay P, Mahanta R and Goswami B N 2010 Multiscale interaction with topography and extreme rainfall events in the North-east Indian region; J. Geophys. Res. (in press), doi: 10.1029/ 2009JD012275.

Guha A and De B K 2009 Lightning electrical characteristics during tropical summer thunderstorm in North-East India; J. Atmos. Sol. Terr. Phys. 71 1365-1373.

Jacobson E A and Krider E P 1976 Electrostatic field changes produced by Florida lightning; J. Atmos. Sci. 33 103-117.

Kaltenböck R, Diendorfer G and Dotzek N 2009 Evaluation of thunderstorm indices from ECMWF analyses, lightning data and severe storm reports; Atmos. Res. 93 $381-396$.

Kamra A K and Pawar S D 2007 Evolution of lightning in an isolated hailstorm of moderate size in the tropics; J. Geophys. Res. 112 D20205, doi: 10.1029/2006JD007820.

Kanjulal T, Basu B, Roy A and Sinha M C 1989 Growth of thunderstorm and latent instability over eastern India; Mausam 40 293-298.

Koteshwaram P and Srinivasan V 1958 Thunderstorm over Gangetic West Bengal in the presmonsson season and the synoptic factors favourable for their formation; Indian J. Met. Geophys. 9 301-312.

Krehbiel P R, Brook M and McCrory R A 1979 An analysis of the charge structure of lightning discharge to ground; J. Geophys. Res. 84 2432-2456.

Krehbiel P R, Brook M, Lhermitte R and Lennon C 1983 Lightning charge structure in thunderstorms; Proc. in Atmospheric Electricity, A. Deepak, Hampton, Va 408-460.

Krider E and Musser J 1982 Maxwell currents under thunderstorms; J. Geophys. Res. 87 C13, doi: 10.1029/ JC087 iC13p11171.

Krishna Rao P R 1966 Thunderstorm studies in India; Indian J. Meteor. Geophys. 12 3-23.

Lang T J and Rutledge S A 2002 Relationships between convective storm kinematics, precipitation, and lightning; Mon. Weather Rev. 130(10) 2492-2506.

Livingston J M and Krider E P 1978 Electric fields produced by Florida thunderstorms; J. Geophys. Res. 83 385-401.

MacGorman D R and Rust D W 1998 The electrical nature of storms; Oxford University Press, 422 pp.
MacGorman D R, Burgess D W, Mazur V, Rust W D, Taylor W L and Johnson B C 1989 Lightning rates relative to tornadic storm evolution on 22 May 1981; J. Atmos. Sci. 46 221-250.

Maier L M and Krider E P 1986 The charges that are deposited by cloud-to-ground lightning in Florida; J. Geophys. Res. 91 13,275-13,289.

Mansell E R, MacGorman D R, Ziegler C L and Straka J M 2002 Simulated three-dimensional branched lightning in a numerical thunderstorm model; J. Geophys. Res. 107 doi: $10.1029 / 2000 J D 000244$.

Marshall T C and Stolzenburg M 2002 Electric energy constraints on lightning; J. Geophys. Res. 107 doi: 10.1029/ 2000JD000024.

McCaul E W, Bailey J, Goodman S J, Blakeslee R, Hall J, Buechler D E and Bradshaw T 2002 Preliminary results from the North Alabama lightning mapping array; Preprints, 21st Conf. on Severe Local Storms, San Antonio, TX, Amer. Meteor. Soc. 427-430.

Moore and Vonnegut 1977 The thundercloud; In: Lightning (ed.) R H Golde (San Diego, Calif.: Academic) 1 $51-98$.

Pawar S D and Kamra A K 2002 Recovery curves of the surface electric field after lightning discharges occurring between the positive charge pocket and negative charge centre in a thundercloud; Geophys. Res. Lett. 29 2108-2111.

Pawar S D and Kamra A K 2004 Evolution of lightning and the possible initiation/triggering of lightning discharges by the lower positive charge center in an isolated thundercloud in the tropics; J. Geophys. Res. 109 doi: 1029/2003JD003735.

Pawar S D and Kamra A K 2007 The end-of-stormoscillation in tropical air-mass thunderstorms; J. Geophys. Res. 112 doi: 10.1029/2005JD006997.

Qie X, Zhang T, Chen C, Zhang G, Zhang T and Wei W 2005 The lower positive charge center and its effect on lightning discharges on the Tibetan Plateau; Geophys. Res. Lett. 32 doi: 10.1029/2004GL022162.

Raman P K and Raghavan K 1961 Diurnal variations of thunderstorms in India during different seasons; Indian J. Meteor. Geophys. 12 115-130.

Ravichandran M and Kamra A K 2004 A new technique to determine the lightning charge location from the electric field vector measurements; J. Atmos. Solar-Terr. Phys. 66 349-362.

Schultz C J, Petersen W A and Carey L D 2009 Preliminary development and evaluation of lightning jump algorithms for the real-time detection of severe weather; J. Appl. Meteorol. Climatol. 48(12) 2543-2563, doi: 10.1175/2009JAMC2237.1

Soula S and Chauzy S 1991 Multilevel measurement of the electric field underneath a thundercloud 2: Dynamical evolution of ground space charge; J. Geophys. Res. 96 $22,327-22,336$.

Standler R B and Winn W P 1979 Effects of coronae on electric field beneath thunderstorms; Quart. J. Roy. Meteor. Soc. 105 285-302.

Steiger S M, Orville R E and Carey L D 2007 Total lightning signatures of thunderstorm intensity over north Texas. Part I: Supercells; Mon. Weather Rev. 135 3281-3302.

Stolzenburg M, Rust W D and Marshall T C 1998 Electrical structure in thunderstorm convective regions 2: Isolated storms; J. Geophys. Res. 103 14,079-14,096.

Vonnegut B and Moore C B 1958 Giant electrical storms; Recent Advances in Atmospheric Electricity (ed.) L G Smith, Pergamon Press, 399-411.

Wiens K C, Rutledge S A and Tessendorf S A 2005 The 29 June 2000 supercell observed during STEPS. 
Part II: Lightning and charge structure; J. Atmos. Sci. 62 4151-4177.

Williams E R 1989 The tripole structure of thunderstorms; J. Geophys. Res. 94 D11, doi: 10.1029/JD094iD11p13151. Williams E R 2001 The electrification of severe storms; Meteorol. Monogr. 28(50) 527-561.

Williams E R, Boldi B, Matlin A, Weber M, Hodanish S, Sharp D, Goodman S, Raghavan R and Buechler D 1999
The behaviour of total lightning activity in severe Florida thunderstorms; Atmos. Res. 51 245-265.

Wilson C R T 1920 Investigations on lightning discharges and on the electric field of thunderstorms; Philos. Trans. A221 73-115.

Wormell T W 1930 Vertical electric currents below thunderstorms and showers; Proc. R. Soc. London A127 $567-590$.

MS received 29 January 2010; revised 9 June 2010; accepted 14 June 2010 